\title{
Variation of Dentin Dysplasia Type I: Report of Atypical Findings in the Permanent Dentition
}

\author{
Cristiane Tomaz ROCHA \\ Paulo NELSON-FILHO \\ Léa Assed Bezerra da SILVA \\ Sada ASSED \\ Alexandra Mussolino de QUEIROZ \\ Department of Pediatric Clinic, Preventive and Community Dentistry, \\ Ribeirão Preto Dental School, USP - University of São Paulo, Ribeirão Preto, SP, Brazil
}

\begin{abstract}
Dentin dysplasia is a rare defect of dentin development with an autosomal dominant pattern of inheritance, which is generally divided into 2 main classes based on the clinical and radiographic appearance of the affected dental tissues: type I, which affects the root portion and type II, which affects the coronal portion of the tooth. This paper reports the case of a child aged 10 years and 8 months with both classic and atypical features of dentin dysplasia type I in the permanent dentition. Only few mandibular teeth were affected and presented clinically normal appearing crowns, moderate to severe mobility, short, blunt or almost absent roots. However, no evidence of pulp chamber obliteration or periapical radiolucencies was found. The clinical and radiographic characteristics observed in this patient are different from those reported in the literature, which suggests that this may be a variation of dentin dysplasia type I expression.
\end{abstract}

Key Words: dentin dysplasia, permanent dentition, dental treatment.

\section{INTRODUCTION}

Dentin dysplasia is a rare defect of dentin development with an autosomal dominant pattern of inheritance $(1,2)$ that affects one in every 100,000 individuals $(3,4)$ and manifests in both primary $(2,5-8)$ and permanent $(2,5,7-9)$ dentitions.

Shields et al. (1) proposed a classification that divided dentin dysplasia into two main classes based on the clinical and radiographic appearance of the affected dental: type I (DD1), "dentin dysplasia," and type II (DD2), "anomalous dysplasia of dentin". Subsequently, DD1 started being referred to as "radicular dentin dysplasia" and DD2 as "coronal dentin dysplasia", in order to indicate the parts of the teeth that are primarily involved (3). A third type of dentin dysplasia or focal odontoblastic dysplasia, with radiographic aspects of both types of dysplasia, has also been described (10).

DD1 is characterized clinically by nearly normal appearing crowns and hypermobility of the teeth $(11,12)$.
Frequent findings include delayed dental eruption pattern $(13,14)$, opaque incisal borders (14), spontaneous premature exfoliation (14), because of the short, blunt, tapering, or even absent roots (1), and discomfort caused by the severe tooth mobility, especially after meals $(2,8,9)$.

Radiographic examination is an important diagnostic tool for identifying this dental anomaly (12), revealing short, blunt and malformed roots, similar to those observed in taurodontic teeth, obliteration of all pulp chambers with crescent-shaped pulp remnants parallel to the cementoenamel junction and several periapical radiolucencies in noncarious teeth $(1,2,5,7,8,14)$.

Microscopic examination of affected teeth reveals a thin enamel layer (7) with atubular secondary dentin, globular organization and, more centrally, spherical structures suggestive of multiple pulp calcifications. Since the mantle dentin is not affected, the teeth have an apparently normal clinical crown (12). 
Although numerous theories have been proposed, the etiology of dentin dysplasia remains unknown. Logan et al. (11) hypothesized that abnormal degeneration and calcification would occur in the dental papilla, resulting in reduced growth and final obliteration of the pulpal space. Sauk et al. (12) suggested the occurrence of an earlier ingrowth of the radicular epithelial sheath, resulting in ectopic dentin formation. Witkop (3) proposed that internal cells of the developing dental organ would be displaced and proliferate in the dental papilla, producing ectopic dentin formation. On the other hand, according to Wesley et al. (15) a failure in the interaction between odontoblasts and ameloblasts would occur, causing differentiation and/or abnormal function of the odontoblasts.

Since there is no consensus in the literature regarding the etiology of dentin dysplasia and considering that this is a rare defect of dentin development, case reports can be useful to help elucidating and understanding some aspects related to this condition. This paper reports the case of a child with dental alterations suggestive of DD1, in whom only few permanent mandibular teeth were affected and different features from those found in the literature were observed.

\section{CASE REPORT}

A 10-year and 8-month-old male patient came to the Pediatric Dentistry Clinic of the Ribeirão Preto Dental School, University of São Paulo, Brazil, for general dental care. The mother reported that the patient was deaf since birth, and no other medical condition was mentioned. Ethics Committee approval (protocol \#2007.1.291.58.5) and parental written informed consent were obtained for case report and disclosure of child's uncovered photographs.

The intraoral clinical examination revealed the presence of the following teeth: $16,15,53,12,11,21$, $22,63,65,26,35,74,73,32,31,41,42,43,44$ and 45. Some of them had large carious lesions or severe coronal destruction, indicating extraction, root canal therapy and/or restoration. Panoramic radiographic examination confirmed that teeth 36 and 46 were missing and showed that teeth 34,35 and 37 presented alteration in the pattern of root formation compared to the contralateral teeth (Fig. 1A). According to the mother, teeth 36 and 46 had been extracted due extensive carious lesions.

Dental care included extraction of tooth 63, endodontic treatment of tooth 16 , restoration of teeth
11 and 16 with composite resin, placement of pit-andfissure sealant in teeth $35,14,15$ and 25 , and placement of a stainless steel crown in tooth 26 .

A new panoramic radiograph taken 1 year later revealed arrest of root formation in teeth 34,35 and 37 (Fig. 1B). Clinically, moderate to severe mobility was observed in teeth 34 and 35, and areas of enamel hypomineralization were found in teeth $31,32,33,42$ and 43. All other teeth presented normal clinical and radiographic appearance. One year later, the panoramic radiographic was repeated and showed no evolution in root formation in teeth 34, 35 and 37 (Fig. 1C). Neither pulp chamber obliteration nor periapical radiolucencies were observed in any of the panoramic radiographic images, which were confirmed by periapical radiograph (Fig. 1D).

The patient's parents and sibling were also examined clinically and radiographically to determine whether hereditary transmission had occurred, but no dental alterations were found.

In the present case, the installation of a functional removable space maintainer was no not necessary because the premolars had already erupted. If teeth 34 and 35 are lost due to the short, blunt and almost absent roots, a space maintainer will be installed and periodically replaced until the patient's facial growth is completed, in such a way that osseointegrated implants can be inserted for further construction of a fixed denture.

The progression of the case is under continuing evaluation. At each follow-up visit scheduled on a 3-month basis, rubber cup/pumice prophylaxis and topical applications of $1.23 \%$ acidulated phosphatefluoride gel (Sultan Topex; DFL Ind. e Com. Ltda., Petrópolis, RJ, Brazil) are performed for professional control of oral hygiene, instructions on oral homecare are reinforced, and the affected regions are examined both clinically (Figs. 1E and 1F) and radiographically.

\section{DISCUSSION}

In this case, the patient presented permanent dentition with normal root development on 3 hemiarches. However, in the left posterior mandibular area, the teeth presented either short, blunt (tooth 35) or almost absent (teeth 34 and 37) roots and consequent hypermobility. Periodontal ligament thickening was observed in tooth 34 due to the incidence of occlusal forces in this region.

The clinical and radiographic findings of this 
case led us to suspect of a variation of DD1, since some of the typical signs of this dental developmental abnormality, such as pulp chamber obliteration and periapical radiolucencies associated with sound teeth $(2,5,14,16)$, were not present.

Scola and Watts (13) proposed a subclassification of DD1 as: total DD1, characterized by the presence of teeth with significantly narrowed or obliterated pulp spaces and permanent teeth with short roots, and subtotal DD1, characterized by permanent teeth with roots of intermediate length. O'Carrol et al. (17) presented another subclassification based on radiographic findings referring to the severity of pulp chamber obliteration, root length and periapical radiolucencies. Four subtypes were proposed: in the first, total pulp chamber obliteration, no root development and multiple periapical radiolucencies are observed; in the second and third, the pulp chamber is less obliterated and present crescent-shaped radiolucent areas, minimal root formation and periapical radiolucencies are less frequent; in the fourth subtype,
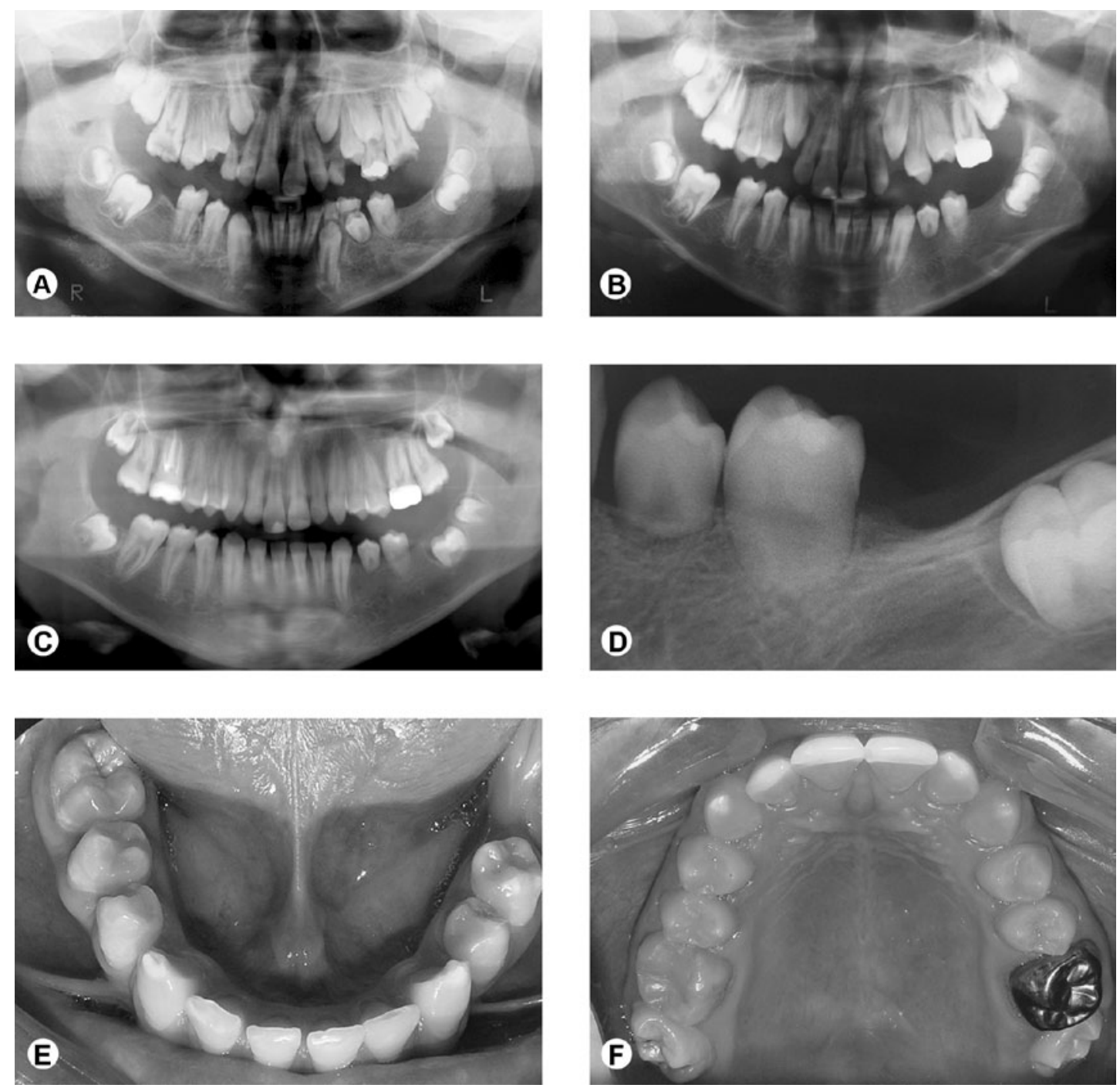

Figure 1. Panel of clinical and radiographic images of the case; $A=$ Panoramic radiograph showing missing teeth 36 and 46 , shortening of root length in teeth 34,35 and 37 in compared to the contralateral teeth, presence of extensive carious lesions in teeth 16 and 26 at the age of 10 years and 8 months; $\mathrm{B}=$ Panoramic radiograph showing arrest of root formation in teeth 34,35 and 37 at the age of 11 years and 9 months; $C=$ Panoramic radiograph showing arrest of root formation in teeth 34,35 and 37 , at the age of 13 . $D=A r r e s t$ of root formation in tooth 35 and absence of root formation in tooth 34. No pulp chamber obliteration or periapical lesion was observed in the periapical radiograph; $\mathrm{E}=$ Intraoral aspect of inferior arch after 4 years of follow up; $\mathrm{F}=\mathrm{Intraoral}$ aspect of superior arch after 4 years of follow up. 
there are radiographically visible and delimited pulp chambers, pulpal nodules are found in the coronal third of the canal, the roots have a significant development and few or no periapical radiolucencies are observed.

Our patient's teeth presented well delimited pulp chambers without pulpal nodules, and short, blunt or almost absent roots. However, no radiolucent areas suggestive of periapical lesions were observed. Therefore, this case of DD1 does not fit in any of the subtypes proposed by O'Carrol et al. (17). The patient presented clinical and radiographic characteristics of DD1 only in the left mandibular area, which agrees with the outcomes of a previous study (18). In that study, only the mandibular left quadrant exhibited typical findings of DD1, while the maxillary right and left molars presented taurodontism. These findings suggest that this type of developmental defect of human dentin may occur due to localized abnormalities in cell proliferation and function, in the same way as observed in regional odontodysplasia (18). Recently, a case of dentin dysplasia involving a single tooth was reported. The authors described as focal odontoblastic dysplasia and suggested that reports of other similar cases are probably needed to determine another type of classification (dentin dysplasia type III) (19).

Van Dis and Allen (4) reported four cases of DD1 in which the radiographic features were somewhat different from those of other cases. Anterior teeth appeared to be less affected than posterior, and tooth loss was less prevalent, suggesting thereby that this type of dentin dysplasia can be divided into 2 subgroups, as proposed by Scola and Watts (13). Variations of DD1 may occur (14), which leads us to assume that the absence of pulp chamber obliteration and periapical lesions associated with sound teeth, as observed in the present case, represents another possible expression of this disorder.

Most DD1 cases have autosomal dominant inheritance, which means that individuals of the same family may be affected (2,13-15). However, reports of cases without signs of a family heritage are found in the literature $(6,16)$ in the same way as described for our patient.

There is no specific treatment for this rare genetic disorder affecting the dentin development of the teeth. Only procedures to avoid the premature loss of hypermobile teeth and to stimulate the normal development of the occlusion can be undertaken. The early diagnosis and continuous follow-up of cases of
DD1 by a pediatric dentist is of paramount importance (6) because the affected teeth have a very unfavorable prognosis due to the short roots and presence of associated periapical radiolucencies. If necessary, space loss due to spontaneous exfoliation of hypermobile teeth can be avoided by the placement of removable space maintainers or orthodontic appliances (20).

While numerous cases of DD1 have been described, some clinical and theoretical issues remain inconclusive. More detailed documentation of cases of DD1 is needed in order to establish relevant clinical and radiographic signs that will aid in the diagnosis of this disorder (9). The presentation of case reports in which classic signs of DD1 are found, but other typical features are not present highlights the clinical and radiographic variations of DD1.

In the present case, both classic (clinically normal appearing crowns, moderate to severe tooth mobility, short, blunt or almost absent roots) and atypical (no evidence of pulp chamber obliteration or periapical radiolucencies in noncarious teeth) features of DD1 were found in the permanent teeth of boy aged 10 years and 8 months.

\section{RESUMO}

A displasia dentinária é uma alteração do desenvolvimento da dentina rara, de origem autossômica dominante, o qual é geralmente dividida em 2 tipos principais baseados na aparência clínica e radiográfica dos tecidos dentais afetados: tipo I, que afeta a porção radicular e o tipo II, que afeta a porção coronária do dente. O objetivo deste trabalho é relatar o caso de um paciente de 10 anos e 8 meses de idade com ambas alterações clássicas e atípicas da displasia dentinária do tipo I na dentição permanente. Alguns dentes da arcada inferior foram acometidos, apresentando-se com coroas clinicamente normais, mobilidade dental de moderada a severa e raízes curtas ou ausentes, porém sem evidência de obliteração das câmaras pulpares e de lesões periapicais. As características clínicas e radiográficas observadas neste paciente foram diferentes daquelas relatadas na literatura, o que sugere que esta possa ser uma variação da expressão da displasia dentinária do tipo I.

\section{REFERENCES}

1. Shields ED, Bixler D, el-Kafrawy AM. A proposed classification for heritable human dentine defects with a description of a new entity. Arch Oral Biol 1973;18:543-553.

2. Ansari G, Reid JS. Dentinal dysplasia type I: review of the literature and report of a family. ASDC J Dent Child 1997;64:429434.

3. Witkop CJ Jr. Hereditary defects of dentin. Dent Clin North Am 1975;19:25-45.

4. Van Dis ML, Allen CM. Dentinal dysplasia type I: a report of four 
cases. Dentomaxillofac Radiol 1989;18:128-131.

5. Seow WK, Shusterman S. Spectrum of dentin dysplasia in a family: case report and literature review. Pediatr Dent 1994;16:437-442.

6. Vieira AR, Modesto A, Cabral MG. Dentinal dysplasia type I: report of an atypical case in the primary dentition. ASDC J Dent Child 1998;65:141-144.

7. Neumann F, Würfel F, Mundt T. Dentin dysplasia type I - a case report. Ann Anat 1999;181:138-140.

8. Shankly PE, Mackie IC, Sloan P. Dentinal dysplasia type I: report of a case. Int J Paediatr Dent 1999;9:37-42.

9. Özer L, Karasu H, Aras K, Tokman B, Ersoy E. Dentin dysplasia type I: report of atypical cases in the permanent and mixed dentitions. Oral Surg Oral Med Oral Pathol Oral Radiol Endod 2004;98:85-90.

10. Eastman JR, Melnick M, Goldblatt LI. Focal odontoblastic dysplasia: dentin dysplasia type III? Oral Surg Oral Med Oral Pathol 1977;44:909-914.

11. Logan J, Becks H, Silverman S Jr, Pindborg JJ. Dentinal dysplasia Oral Surg Oral Med Oral Pathol 1962;15:317-333.

12. Sauk JJ Jr, Lyon HW, Trowbridge HO, Witkop CJ Jr. An electron optic analysis and explanation for the etiology of dentinal dysplasia. Oral Surg Oral Med Oral Pathol 1972;33:763-771.

13. Scola SM, Watts PG. Dentinal dysplasia type I. A subclassification. Br J Orthod 1987;14:175-179.
14. Kalk WW, Batenburg RH, Vissink A. Dentin dysplasia type I: five cases within one family. Oral Surg Oral Med Oral Pathol Oral Radiol Endod 1998;86:175-178.

15. Wesley RK, Wysoki GP, Mintz SM, Jackson J. Dentin dysplasia type I. Clinical, morphologic, and genetic studies of a case. Oral Surg Oral Med Oral Pathol 1976;41:516-524.

16. Toomarian L, Mashhadiabbas F, Mirkarimi M, Mehrdad L. Dentin dysplasia type I: a case report and review of the literature. J Med Case Reports 2010;4:1-6.

17. O'Carroll MK, Duncan WK, Perkins TM. Dentin dysplasia: review of the literature and a proposed subclassification based on radiographic findings. Oral Surg Oral Med Oral Pathol 1991;72:119-125.

18. Kosinski RW, Chaiyawat Y, Rosenberg L. Localized deficient root development associated with taurodontism: case report. Pediatr Dent 1999;21:213-215.

19. Naik VV, Kale AD. Dentin dysplasia: Single-tooth involvement? Quintessence Int 2009;40:183-186.

20. Brenneise CV, Dwornik RM, Brenneise EE. Clinical, radiographic, and histological manifestations of dentin dysplasia, type I: Report of case. J Am Dent Assoc 1989;119:721-723.

Accepted November 16, 2010 